\title{
POLÍTICAS DO ESQUECIMENTO: TRAUMA E FANTASMAGORIA NAS CULTURAS BRASILEIRA E PORTUGUESA
}

\author{
Lisa Carvalho Vasconcellos ${ }^{1}$
}

Resumo: A escassa produção de textos - literários ou não - sobre a Colônia Correcional da Ilha Grande, no Brasil, e o campo de prisioneiros de Tarrafal, na África portuguesa, dois importantes centros de detenção política, pode ser tomada como um índice das dificuldades enfrentadas pelas culturas desses países na elaboração das práticas autoritárias às quais ambos foram submetidos ao longo de quase todo o século XX. Escritos sob o influxo da dor e do trauma, mas também do interdito e do recalque (cf. FREUD, 2010), muitos dos testemunhos, dos depoimentos e dos textos ficcionais (memorialísticos e autobiográficos em sua maioria) que procuraram pensar tais assuntos estão marcados pelo silenciamento de conflitos e pela denegação - novamente em sentido freudiano - da violência experienciada. Nesse sentido - e conforme propõem Roberto Vecchi e Margarida Calafate Ribeiro (cf. RIBEIRO \& VECCHI, 2011) no que diz respeito à memória poética da Guerra Colonial lusa - os conceitos de fantasmagoria, rastro e resto propostos por Walter Benjamin podem funcionar como provocação teórica para o entendimento dos textos literários e da cultura letrada desses países (assim como das práticas políticas que lhe servem de horizonte). No trabalho que ora propomos, o objetivo será estudar comparativamente os livros Memórias do cárcere (1953), de Graciliano Ramos, e Tarrafal, o pântano da morte, de Cândido de Oliveira, procurando ver como ambas as obras - ao mesmo tempo em que se reconhecem assombradas pelos fantasmas do silenciamento e da repressão - decidem enfrentá-los, usando o próprio texto como arma e mediação.

Palavras-chave: Ilha-prisão, literatura luso-brasileira, trauma e fantasmagoria.

Abstract: There is scarce literary production concerning the Colonia Correcional da Ilha Grande e the Portuguese prisoners camp of Tarrafal. Given that those were major correctional institutions, we take that lack of literary works as an index of the problems faced both by Portugal and Brazil in dealing with the memories of the dictatorial regimes that took place in those places during the 20th century. Written under the influx of pain and trauma, the testimonial and fictional texts that deal with those prisons are marked by conflicts and denegation (Freud, 2010) towards the violence experienced by their authors. In such a context - according to Roberto Vecchi and Margarida Calafate Ribeiro (RIBEIRO \& VECCHI, 2011) - the concepts of phantasmagoria, remain and trace (spuren) proposed by Walter Benjamin can work as a theoretical provocation that could help the understanding of the literary culture that rises from violent contexts. In this paper we will do a comparative study of the books Memórias do cárcere (1953), by Graciliano Ramos and Tarrafal: o campo da morte (1978), by Cândido de Oliveira. We seek to understand how both works are haunted by the ghosts of silence and repression, but decide to face then using literature as tools.

Keywords: Prison Island, luso-brazilian literature, trauma and phantasmagoria.

1 Doutora em Teoria Literária e Literatura comparada pela USP. Pesquisadora vinculada ao Grupo de Estudos Comparados de Literaturas de Língua Portuguesa.UFBA/CNPq. E-mail: lisa.vasconcellos@gmail.com

Literatura e Autoritarismo, Santa Maria, n. 31: A experiência do confinamento, jan.-jun. 2018, p. 5-14. - ISSN 1679-849X 
1. Ainda é pouco discutido e debatido o fato de que, entre 1936 e 1974, ou seja, durante um período de quase quarenta anos, um campo de concentração de inspiração nazifascista foi mantido pelo Estado Novo português com o objetivo de abrigar dissidentes políticos, lideranças populares, sindicalistas, revolucionários africanos e até criminosos comuns. $\mathrm{O}$ campo, denominado inicialmente "Colônia Penal de Cabo Verde" e mais tarde rebatizado como "Campo de trabalho de Chão Bom", ficou popularmente conhecido por Tarrafal, ou ainda, pela triste alcunha de "Campo da morte lenta". O epíteto tem sua razão de ser. A Ilha de Santiago, local escolhido para a localização da prisão, se caracterizou desde sempre por condições geográficas e climáticas particularmente adversas à vida humana. Somados a elas o isolamento, o descaso e os maus tratos, o resultado foi um saldo significativo de perdas humanas, vítimas não do assassinato ou extermínio imediato, mas dos muitos anos passados sob um regime de desnutrição, doença e intempérie.

Entre 1936 e 1954, o campo abrigou, entre idas e vindas, 334 (AQUINO, 1978, pp. 285296) prisioneiros - comunistas, anarquistas, republicanos e também criminosos comuns sem orientação ideológica mais clara. Destes, $32^{2}$ (TAVARES, 2007, p. 259) morreram - a grande maioria decorrente da malária, enfrentada, de começo, sem qualquer recurso ou medicamento. Fechado em 1954, por causa de pressões internacionais, o campo foi reaberto em 1961 para abrigar os nacionalistas africanos envolvidos na guerra colonial que então tinha início. O campo duraria mais treze anos, sendo que seu fechamento definitivo sob o regime português só se daria em 1974, por ocasião da Revolução de 25 de Abril.

É nossa hipótese que esse campo constitua, junto com Ilha Grande, no Brasil, um paradigma daquilo que vamos chamar de Ilha-prisão - isto é, um lugar afastado dos centros de poder, cercado pelo mar, onde é possível instituir um regime político, jurídico e militar próprio. Esse regime se caracterizaria por sua vez pela ausência de garantias institucionais que protegessem a população interna, de modo a permitir - em muitos casos seria melhor dizer: de modo a causar necessariamente - a sua destruição.

Nessa definição, nos inspiramos claramente em Giorgio Agamben, que vai conceber o "estado de exceção" não como um regime alternativo ao estado de direito, mas como uma situação paradoxal na qual, através de um dispositivo legal, se abole o próprio estado de direito. Em linhas gerais, como o próprio nome já anuncia, o estado de exceção se opõe ao estado de direito ou simplesmente ao estado normal das coisas, na medida em que susta direitos e garantias legais e interrompe os procedimentos (eleições, votações etc.) típicos dos regimes democráticos. O estado de exceção não implica, pois, a criação de um regime jurídico alternativo - como o estado de guerra, por exemplo - mas a suspensão do regime jurídico como um todo. É assim um dispositivo de difícil definição, situando-se entre o direito e a política (AGAMBEN, 2004, p. 12). Não é sem razão que diferentes países divergem sobre sua instauração, sendo que ela pode ou não ser prevista constitucionalmente (fato, em si mesmo, profundamente contraditório). Isso não impediu, entretanto, que regimes de exceção tenham sido invocados com uma frequência alarmante durante os últimos cem anos em estados centrais, como Itália, Alemanha, França ou Estados Unidos. Essa estranha

2 O número não é exato. Acácio Tomás de Aquino registra 32 mortos e é nele que nos baseamos aqui. Cândido de Oliveira (OLIVEIRA, 1974) registra, entretanto, 34 mortos. Recentemente, o jornalista José Vicente Lopes contou 33 campas no antigo cemitério do campo (LOPES, 2010). 
e incômoda coincidência entre aquilo que julgamos ser o auge da democracia moderna (as nações ocidentais durante o século XX) e regimes que são tudo menos democráticos leva Agamben a eleger o estado de exceção como paradigma político dominante na contemporaneidade.

Acreditamos que esse paradigma se faz presente também nas Ilhas-prisão, com uma diferença básica. O fenômeno abordado por Agamben é algo que está profundamente ligado ao caráter de contingência de certos eventos históricos. Guerras, catástrofes naturais, epidemias ou revoluções são algumas das situações extremas que precipitam o estado de exceção, que é invocado então como único meio de defesa da integridade nacional e dos valores democráticos do país ${ }^{3}$. Nesse caso, o estado de exceção se institui como um parêntesis na história democrática de um estado, um hiato no tempo, precipitado por acontecimentos também dentro do tempo. No caso da Ilha-prisão, entretanto, a exceção não se dá no tempo, mas no espaço. Aqui, não é o evento histórico, mas a geografia que favorece a excepcionalidade jurídica. O afastamento do continente e a falta de acessibilidade não são, nesse contexto, fatores contingenciais, mas são propositalmente pensados pelos estadistas no duplo sentido de dificultar a fuga ${ }^{4}$ de prisioneiros e barrar seu contato com qualquer grupo - imprensa, associações de classe, famílias - que se dispusesse a fiscalizar sua situação.

Tanto em Ilha Grande como em Tarrafal, a exceção é uma situação reconhecida pelos prisioneiros. A longa viagem até o continente (AQUINO, p. 59; RAMOS, p. 137), a dificuldade de acesso a jornais, revistas e mesmo às cartas enviadas por parentes (VÁRIOS, 256), a independência em relação aos órgãos sediados no continente (OLIVEIRA, p. 39), a paranoia gerada pelo isolamento e pela falta de notícias (LESSA, 178) são alguns dos principais tópicos da literatura produzida sobre esses locais e dão testemunha de como o caráter de exceção era vivido na prática pelos prisioneiros.

Mas, se esses relatos enfatizam a profunda diferença entre a vida no campo e o estatuto de normalidade, a própria existência da Ilha-prisão não deixa de estar intimamente ligada às práticas autoritárias que vigoram no continente. Em ambos os contextos analisados, o campo serve, ao mesmo tempo, como ensaio (lugar de experimentação política e social) e radicalização das práticas de dominação existentes dentro dos respectivos países.

2. Em Origens do totalitarismo, Hannah Arendt defende que as técnicas de extermínio e repressão em massa colocadas em prática pelos estados totalitários foram pensadas propositalmente como forma de instituir um terrorismo de estado, cujo objetivo seria disciplinar a população como um todo.

A diferença fundamental entre as ditaduras modernas e as tiranias do passado está no uso do terror não como meio de extermínio e amedrontamento dos opo-

3 Como ressalta Agamben, é impossível ignorar a ironia de uma situação na qual a defesa da democracia serve como desculpa para a total abolição dessa mesma democracia.

4 Tanto em Tarrafal como em Ilha Grande, tentativas de fuga foram ensaiadas. Na maior parte das vezes, entretanto, os evadidos, incapazes de chegar ao continente, eram apreendidos depois de alguns dias. Na ilha brasileira, há alguns poucos casos documentados de escapes de sucesso (SANTOS, 2009) e, em Portugal, é bem conhecida a famosa fuga que Álvaro Cunhal e seus companheiros empreenderam para sair de Peniche, uma península que, por suas características, também poderia ser classificada sob a rubrica de Ilha-prisão. Nessas raras exceções, entretanto, os prisioneiros obtiveram ajuda provinda tanto do exterior como de pessoal interno à ilha. Em Tarrafal, nenhuma fuga foi bem-sucedida. 
nentes, mas como instrumento corriqueiro para governar as massas perfeitamente obedientes. O terror, como o conhecemos hoje, ataca sem provocação preliminar, e suas vítimas são inocentes até mesmo do ponto de vista do perseguidor (ARENDT, 1989, p. 26).

Resumindo o argumento de Arendt, se os totalitarismos modernos, nazistas e stalinistas mais especificamente, elegeram judeus ou dissidentes políticos como seus inimigos não é porque esses fossem ameaça real as suas respectivas governanças. O lager, da Alemanha nazista, e os campos de trabalho soviéticos, na realidade, faziam parte de uma estratégia complexa montada com o objetivo de infligir terror ao resto da população e mantê-la assim sob controle. Os demais cidadãos que testemunhavam o extermínio dos seus pares, aterrorizados, se tornavam uma massa dócil, disposta a cooperar com a situação no lugar de se revoltar contra as injustiças do sistema. Dentro dessa lógica, explica Arendt, não faz sentido para os regimes totalitários visar os culpados ou os inimigos; é justamente a perseguição de pessoas aleatórias - ou ainda, inocentes como quer a autora - que garante o terror. Sabendo que a repressão não segue qualquer lógica, todos se sentem inseguros, todos temem por si e por seus familiares, todos se limitam a ficarem felizes e agradecidos por não serem eles mesmos objeto de perseguição do estado.

Da mesma maneira que Arendt vincula a realidade dos lager alemães e dos campos de trabalho soviéticos aos totalitarismos de Estado nazistas e stalinistas, acreditamos que é possível vincular as realidades dos campos portugueses e brasileiros aos regimes autoritários que vigoraram tanto no Brasil quanto em Portugal ao longo do século XX. O terrível imaginário que ainda hoje cerca ilhas como Fernando de Noronha, na costa brasileira, ou a própria prisão de Tarrafal, nosso exemplo aqui, é prova do efeito que a simples existência desses lugares tiveram sobre a população do continente. O degredo para ilha não era visto como um castigo qualquer, mas como uma punição exemplar temida por todos (SANTOS, 2009).

Percebe-se então que o conceito de Ilha-prisão que queremos desenvolver aqui se desenha a partir de um contraditório cruzamento. Por um lado, ela se institui como espaço de exceção onde se abolem o direito individual e as garantias constitucionais, se diferenciando e se contrapondo ao continente como um espaço outro, separado por isso mesmo por mares e obstáculos geográficos. Por outro, ela é parte central na manutenção do sistema de repressão do regime como um todo, é continuação e radicalização das práticas autoritárias que vigoram no continente. A ilha se institui, então, a partir de um duplo e contraditório estatuto: é aquilo que existe de mais alheio - a exceção, como formula Agamben - e de mais central no que diz respeito ao estado das coisas (como quer Arendt). É então a periferia e o cento do sistema, é aquilo que não respeita a lei, mas a institui. É um lugar, por isso mesmo, impossível e os relatos que dele partem marcam isso muito bem identificando a ilha e aqueles que nela habitam com a fantasmagoria. A seguir, gostaríamos de investigar como isso se dá em dois dos principais textos produzidos sobre a Ilha-prisão: Memórias do cárcere, de Graciliano Ramos, e Tarrafal, o pântano da morte, de Cândido de Oliveira. 
3. Publicado postumamente em 1953, em quatro volumes, Memórias do cárcere relata a experiência que o próprio Graciliano Ramos viveu como prisioneiro do Estado Novo brasileiro. Dividido inicialmente em quatro partes - Viagens, Pavilhão dos Primários, Colônia Correcional e Casa de Correção -, contempla o período de aproximadamente um ano, do momento em que o autor foi preso às vésperas da sua liberação. O terceiro volume (ou a terceira parte, como querem as edições atuais) é dedicado exclusivamente à experiência da Ilha Grande, mas acreditamos que a leitura do livro como um todo compõe um dos testemunhos mais completos que temos em português sobre a Ilha-prisão. Problemas ligados à realidade da ilha não se limitam à parte dedicada a ela, mas contaminam aquilo que a antecede, na forma de prognóstico, e sucede, na forma de trauma e luto. Gostaríamos de selecionar aqui dois trechos de momentos que antecipam a realidade da ilha, mas que, justamente por isso, a iluminam com uma clareza rara. No primeiro, o sentimento de insegurança e indefinição toma forma de sonhos sombrios, na primeira noite dormida fora de casa:

Deitei-me e fiquei a virar-me e a revirar-me no lençol dobrado, tentando em vão chamar o sono. Realmente não posso dizer se dormia ou velava: feriam-me os sentidos uma faixa alvacenta que me banhava os travesseiros, o vulto indeciso do capitão, a mesinha, as cadeiras, a sentinela encostada ao fuzil, no alpendre uma nova sentinela a amofinar-se no serviço cacete; mas às vezes tudo se embrulhava, entre as visões concretas esboçavam-se fantasmagorias - e era-me impossível saber onde me achava, porque me estirava no colchão alheio, depois de solavancos infinitos na estrada de ferro. A minha vida anterior se diluía, perdia-se além daquele imenso espaço de vinte e quatro horas. Um muro a separar-me dela, a altear-se, a engrossar, e para cá do muro - nuvens, incongruências. (RAMOS, 1993, p. 67)

Os fantasmas são com certeza o resíduo do que historicamente se escoou, são uma permanência, um reaparecimento do passado não inteiramente passado, mas são também as suas representações, as suas ficções, as fantasias com que se reconfiguram (VECCHI, 2010, p. 114).

A imagem que o trecho parece perseguir é a do fantasma: faixa alvacenta, vulto indeciso, nuvens, fantasmagorias são alguns dos termos que o nomeiam aqui. Signo de uma situação intermediária, entre o sono e a vigília, mas também entre a vida comum e a exceção, o fantasma se imiscui ao cotidiano do quartel e contamina os objetos concretos que surgem, no trecho, em meio a imagens de sombra e de sonho.

Falar de fantasma é, entre muitas outras coisas, falar de retorno. É também falar de trauma, daquilo que morreu e retornou, daquilo que foi silenciado, mas que insiste na sua presença.

$\mathrm{Na}$ tradição, o fantasma é o espectro, isto é, o reaparecimento do defunto pela sua imagem residuária e evanescente (VECCHI, 2010, p. 114). O arquétipo literário do fantasma é o pai de Hamlet - preso entre dois mundos, o dos vivos e o dos mortos, depois de ter sofrido uma morte criminosa e injusta. Cabe ao filho punir os responsáveis, corrigir o mal- 
feito para que o pai possa então descansar em paz. O fantasma marca esse lugar ambíguo, a presença de uma ausência, aquilo que se foi, mas insiste em perturbar. Aqui, entretanto, é o próprio eu que se vai do mundo, sugado pelo furacão do sistema carcerário, isolado de família e amigos, separado do seu meio por um muro metafórico que logo se tornará concreto.

Nesse contexto, todas as certezas fraquejam e até os roteiros e as narrativas pré-determinadas que organizam a expectativa do que é uma prisão falham: "Nada afinal do que eu havia suposto: o interrogatório, o diálogo cheio de alçapões, alguma carta apreendida, um romance com riscos e anotações, testemunhas sumiram-se. Não me acusavam, suprimiamme" (RAMOS, 1993, p. 52). É o próprio eu que é então suprimido, desaparecido, que não faz mais parte desse mundo, mas insiste em percebê-lo na materialidade dos móveis e das multiplicáveis (o capitão, a sentinela, a segunda sentinela) figuras de vigilância que o cercam. Mais tarde, no barco que o levará ao Rio de Janeiro junto a outros degredados, o autor constatará a falta de lugar que coube a si e àqueles que como ele eram perseguidos pelo regime:

O mundo se tornava fascista. Num mundo assim, que futuro nos reservariam? Provavelmente não haveria lugar para nós, éramos fantasmas, rolaríamos de cárcere em cárcere, findaríamos num campo de concentração. Nenhuma utilidade representávamos na ordem nova. Se nos largassem, vagaríamos tristes, inofensivos e desocupados, farrapos vivos, velhos prematuros; desejaríamos enlouquecer, recolher-nos no hospício ou ter coragem de amarrar uma corda ao pescoço e dar o mergulho decisivo (RAMOS, 1991, p. 179).

Nesse, que é o segundo trecho de análise escolhido por nós, novamente a figura do fantasma aparece. Agora claramente identificada ao próprio autor e a outros que como ele são objeto da perseguição fascista: "éramos fantasmas, rolaríamos de cárcere em cárcere, findaríamos num campo de concentração". Fantasma aqui é metáfora para falta de lugar, e a consequente deriva, associada àqueles que divergem do regime, agora tão onipresente e universal que compreende o mudo dos vivos como um todo.

Mario Sznajder, estudioso especializado em regimes de matiz fascista, nos explica que as democracias se estruturam a partir de um centro duro, que é o indivíduo humano na sua singularidade. As ideologias nazifascistas, entretanto, se erigem em torno de um núcleo diferente, mas igualmente importante para elas: a comunidade. O resultado é que

o fascismo não reconhece o direito natural à vida (o direito humano básico), nem o direito a integridade física e todas as liberdades que derivam disso, mas propõe uma visão orgânica na qual o bem-estar do indivíduo está subordinado ao da comunidade (nação-raça) e às leis que esta desenvolve ao longo da história e que impelem seu bem-estar, mesmo que para consegui-lo seja necessário o sacrifício individual (SZNAJDER, 2010, p. 32).

O raciocínio de base explicitado por Sznajder nos ajuda a compreender também a natureza das perseguições empreendidas por governos fascistas. Tomando como centro ne- 
vrálgico uma noção pré-determinada de grupo (que se materializa necessária e unicamente como raça ou nação), regimes de natureza autoritária passaram a tomar como inimigos todos aqueles que não se conformavam com a ideologia nacional dominante ou que não se encaixavam nos modelos (sociais, étnicos, sexuais ou religiosos) tidos como aceitáveis por essas mesmas comunidades nacionais ${ }^{5}$. Dentro de um regime que tem pouco apreço pela vida humana e que os vê como ameaça, dissidentes ou minorias são passíveis de serem sacrificados sem qualquer consequência ${ }^{6}$.

Nesse contexto, o devaneio que Ramos faz no porão do Manaus, navio que o trouxe do Nordeste para a costa do Rio de Janeiro, tem o caráter de um insight dentro dos meandros do regime. A força do trecho está no fato de que as metáforas e figurações usadas aqui para falar dos sentimentos nebulosos de um prisioneiro a caminho de seu destino ganham, com o decorrer da narrativa de Ramos e dos eventos históricos que a sucederam, o caráter de fato concreto. O perder-se - a deriva que culminou no apagamento individual, na loucura, no suicídio ou no mergulho/ desaparecimento total, sem túmulos, sem notícias, sem rastros ou restos que permitam uma assimilação (como lembra Vecchi, na esteira de Benjamin) - foi frequentemente o destino das vítimas dos regimes ditatoriais. O próprio Graciliano Ramos foi transferido de prisão em prisão até terminar na pior de todas, a Colônia Penal de Ilha Grande, lugar onde sua saúde e sua segurança pessoal foram seriamente ameaçadas.

4. Semelhante foi a trajetória de Cândido Fernandes Plácido de Oliveira (1896-1958), uma figura que viveu do outro lado do Atlântico, e que foi autor de formulações muito parecidas no que diz respeito às prisões e aos campos mantidos pelo fascismo português. Oliveira é um sujeito singular em meio aos muitos que escreveram e testemunharam sobre o Tarrafal. Na juventude, foi um famoso jogador de futebol, tendo atuado no Benfica; na idade madura se tornou técnico, jornalista esportivo, teve cargos no estado. Ou seja, foi uma figura pública e popular, mas que manteve também uma importante militância ligada a grupos de esquerda e também à $\mathrm{SOE}^{7}$ britânica. Isso acabou determinando a sua prisão e posterior envio para o campo de Tarrafal, onde permaneceu 18 meses (1942-1944). Os próprios rumos da guerra acabam determinando a sua soltura e, depois de livre, Oliveira se empenhou na escrita de um dos mais importantes relatos de denúncia sobre a Ilha-prisão.

\footnotetext{
5 Nesse sentido, uma diferenciação importante precisa ser feita. Parece-nos que para os regimes nazifascistas (ou inspirados neles) que vigoraram em países de origem latina - Itália, Portugal, Espanha, Brasil e outros países da América Latina, por exemplo - o grupo corresponde à nação Daí ser perpetrada nesses lugares basicamente uma perseguição política, na qual eram entendidos como elementos estranhos aqueles que não se conformavam com a ideologia nacional dominante. Para o nazismo alemão, entretanto, o grupo correspondia à raça, ou ainda ao grupo étnico majoritário. Daí a consequente perseguição de judeus e ciganos durante o Terceiro Reich, por exemplo.

6 Aproximamo-nos aqui novamente de Agamben. No primeiro volume da sua trilogia sobre o poder soberano e a vida nua, o pensador italiano recupera uma figura ambígua do direito romano, o Homo sacer -- pessoa que, por ter cometido algum crime, era considerada sacrificável pelo resto da sociedade. Assim, embora a justiça não se desse ao trabalho de condená-lo a morte, caso essa viesse a ocorrer por mão alheia, não seria considerada uma infração.
}

7 A SOE, Special Operations Executive, foi uma organização mantida pelo governo britânico durante a Segunda Guerra Mundial. Seu objetivo era apoiar e incrementar movimentos de resistência que se opusessem à expansão nazista dentro da Europa. Em Portugal, foi responsável por criar planos de contingência e sabotagem, que seriam colocados em prática no caso de uma invasão alemã. 
Tarrafal, o pântano da morte é um misto de ensaio e testemunho, claramente escrito com o propósito de denunciar as atrocidades do campo em um momento em que ele ainda estava em vigor. As denúncias, entretanto, nunca se concretizaram a tempo, uma vez que o livro só foi encontrar ambiente político para ser publicado em 1974 - mais de 15 anos após a morte do autor. Para além das semelhanças circunstanciais - a matéria da prisão, a publicação póstuma etc. -, Tarrafal, o pântano da morte é marcado por alguns dos temas e imagens comuns a Memórias do cárcere já abordados aqui. O fantasma é uma das metáforas que volta a aparecer, identificada aqui aos presos que Oliveira vê ao adentrar o campo pela primeira vez:

Que homens eram aqueles? Eram seres humanos que tínhamos ali perto, na nossa frente? Certamente. Mas pareciam fantasmas, arrastando-se como autómatos articulados! Rapazes novos, na sua maioria à roda dos trinta anos, refletindo velhice precoce. Vincos de martírio cavados fundo nos rostos esquálidos, de tom baço, da cor típica do paludismo como se os farrapos de caqui amarelo do vestimento (sic.) da ordem se espelhassem nas suas magras faces. (...) (OLIVEIRA, 1974, p. 67)

Nas suas primeiras interrogações o trecho ecoa preocupações de Primo Levi (É isto um homem?) e Robert Antelme (A espécie humana), que, nos títulos dos seus respectivos trabalhos, já confessam a intenção de usar a experiência do campo de concentração como mote para pensar o estatuto do humano como um todo. Como acontece às personagens dos dois clássicos, as figuras do trecho foram de tal maneira minadas e reduzidas pelas condições do campo, que é quase difícil reconhecê-las enquanto homens. Nesse sentido, a cor amarelada da pele dos presos deixa de ser sintoma da malária que grassava em Cabo Verde e que viria a ser a principal causa das mortes do campo - e passa a ser metáfora de uma realidade cruel: a das condições externas que rebaixam o ser humano ao ponto da distorção: contaminados pela cor cáqui dos velhos uniformes, os presos não parecem mais pessoas, mas autômatos, bonecos desumanizados.

O destino daqueles que chegaram de fato a perecer dentro da prisão também é narrado de maneira fantasmática. No lugar do drama dos doentes, da violência gritante e escancarada das mortes reais, Oliveira alude àqueles que se foram de maneira encoberta e elíptica:

Uma brigada de presos vai ao refeitório buscar uma mesa. Escolhe-se, claro, a mesa mais velha...Porventura aquela onde comia o morto. Com ela se vai fabricar o caixão. E enquanto se não constrói uma outra, no renque de mesas do longo e triste refeitório ficará um claro, a dizer que, durante aqueles dias, mais um preso morreu! (OLIVEIRA, 1974, p. 109)

$\mathrm{Na}$ falta de melhores cerimônias fúnebres - os presos não tinham autorização para acompanhar o caixão ao pequeno cemitério que foi instaurado fora das muralhas do campo -, o vazio no refeitório era o único adeus deixado pelo morto. 
Ora, sabemos que "a instalação de um túmulo [...] com a localização dos despojos e a identificação dos mortos" (RIBEIRO; VECCHI, 2013, p. 93) é parte essencial do processo de luto. Roberto Vecchi e Margarida Calafate Ribeiro nos lembram, entretanto, de que uma das marcas da modernidade é justamente a dificuldade de nomear e dar um lugar à perda. Ao analisar a poesia de guerra portuguesa, os dois autores vão concluir que os fantasmas, restos, retornos de todo tipo que a povoam, são índices de uma perda que se recusa a ser incorporada em termos de luto freudiano ${ }^{8}$. Ao final das contas, o que a literatura desse país nos diz é que depois de anos de ditadura, guerra e repressão está-se em face a um passado traumático e inassimilável.

No trecho, o fantasma é atualizado no refeitório por meio do espaço vazio deixado por uma mesa. Índice do ocultamento, da exceção, da morte inglória e obscura (OLIVEIRA, 1974, p.109), o vão vai assombrar os demais presos até que a próxima perda venha substituí-lo. A imaterialidade da experiência da falta, que se dá sem ritos ou celebrações, sem nomes ou registros, se limita aqui então ao fantasma. Fantasma esse que ainda nos assombra e continuará a assombrar até que os mortos tenham, como manda a tradição, a sua justiça e o seu descanso.

\section{REFERÊNCIAS}

AGAMBEN, Giorgio. Estado de exceção. São Paulo: Boitempo, 2004. Tradução Iraci Poleti.

AGAMBEN, Giorgio.. Homo sacer: o poder soberano e a vida nua I. 2. ed. Belo Horizonte: Editora UFMG, 2010. Tradução Henrique Burigo.

AGAMBEN, Giorgio. O que resta de Auschwitz. São Paulo: Boitempo, 2008. Tradução Selvino Assmann.

ANTELME, Robert. A espécie humana. Rio de Janeiro: Record, 2014. Tradução Maria de Fátima Oliva do Coutto.

AQUINO, Acácio Tomás de. O segredo das prisões atlânticas. Torres Vedras: A regra do jogo, 1978.

ARENDT, Hannah. Origens do totalitarismo. São Paulo: Companhia das Letras, 1989. Tradução Roberto Raposo.

BENJAMIN, Walter. O anjo da história. Trad. João Barrento. Lisboa: Assírio \& Alvim, 2010. Tradução João Barrento.

BENJAMIN, Walter.. Teses sobre a história. In: Magia e técnica, arte e política. São Paulo: Brasiliense, 1994.

CARNEIRO, Maria Luiza Tucci; CROCI, Federico (orgs). Tempos de fascismos: ideologia - intolerância

8 Cf. Freud, "Luto e melancolia", 1976. 
- imaginário. São Paulo: Edusp/ Imprensa oficial/ Arquivo público do Estado de São Paulo, 2010.

FREUD, Sigmund. "O estranho". In: Edição Standard Brasileira das Obras completas de Sigmund Feud. v. XVII. Rio de Janeiro: Imago, 1976. Tradução de Jaime Salomão.

BENJAMIN, Walter.. "Luto e melancolia". In: Edição Standard Brasileira das Obras completas de Sigmund Feud. v. XIV. Rio de Janeiro: Imago, 1976. Tradução de Jaime Salomão.

LESSA, Orígenes. Ilha grande: do jornal de um prisioneiro de guerra. São Paulo: Companhia Editora Nacional, 1933.

LEVI, Primo. É isto um homem? Rio de Janeiro: Rocco, 1988. Tradução Luigi Del Re.

OLIVEIRA, Cândido de. O pântano da morte. Lisboa: Editorial República, 1974.

OLIVEIRA, Gilberto. Memória viva do Tarrafal. Lisboa: Avante, 1987. (1936-1954): a origem e o quotidiano. Lisboa: Colibri, 2007.

RAMOS, Graciliano. Memórias do cárcere. 2 v. São Paulo: Record, 1993.

RIBEIRO, Margarida; VECCHI, Roberto. “A memória poética da Guerra Colonial de Portugal na África”. In: SEDLMAYER, Sabrina; GINZBURG, Jaime. Walter Benjamin: rastro, aura e história. Belo Horizonte: Editora UFMG, 2012.

SANTOS, Myrian Sepúlveda dos. Os porões da república: a barbárie nas prisões da Ilha Grande: 18941945. Rio de Janeiro: Garamond, 2009.

VÁRIOS. Tarrafal, testemunhos. Lisboa: Caminho, 1978.

VECCHI, Roberto. Excepção atlântica: pensar a literatura da guerra colonial. Porto: Afrontamento, 2010.

Filme

Tarrafal, memórias do campo da morte lenta (2013), de Diana Andringa. 